\title{
Safety of corticosteroids in the treatment of acute respiratory disease in children: a systematic review and meta-analysis
}

\author{
Xiaoyun Yang, Hui Jin \\ Department of Pediatrics, The First Affiliated Hospital of Dalian Medical University, Dalian, China \\ Contributions: (I) Conception and design: Both authors; (II) Administrative support: H Jin; (III) Provision of study materials or patients: X Yang; \\ (IV) Collection and assembly of data: X Yang; (V) Data analysis and interpretation: Both authors; (VI) Manuscript writing: Both authors; (VII) Final \\ approval of manuscript: Both authors. \\ Correspondence to: Hui Jin. Department of Pediatrics, The First Affiliated Hospital of Dalian Medical University, 222 Zhongshan Road, Xigang \\ District, Dalian 116011, China. Email: jhlxc_6@163.com.
}

\begin{abstract}
Background: Oral corticosteroids are often used to treat acute asthma or asthma caused by respiratory tract infection in adult patients, but the effect of oral corticosteroids in young children is still controversial. We conducted a meta-analysis of controlled clinical studies to examine the effect of oral corticosteroids in children with respiratory diseases.

Methods: Embase, PubMed, Web of Science, Ovid, ClinicalTrials.org from January 2000 to August 2021 were searched for randomized control trials related to the treatment of pediatric respiratory diseases with corticosteroid drugs using the keywords "corticosteroids" and "acute respiratory diseases". After screening the articles, Revman 5.4 software was used for the analysis.

Results: A total of 8 articles (comprising 2,327 patients, 4 kinds of corticosteroids, and 3 types of pediatric respiratory disease) were included in the meta-analysis. The results showed that the length of hospital stay of patients in the experimental group treated with corticosteroids was shorter than that of patients in the control group [mean difference $=-2.03,95 \%$ confidence interval $(\mathrm{CI}):-2.91,-1.14 ; \mathrm{P}<0.00001]$. Further, the number and proportion of uncured patients after 3 days of treatment were lower in the experimental group than the control group [odds ratio $(\mathrm{OR})=0.55,95 \% \mathrm{CI}: 0.42,0.72 ; \mathrm{P}<0.00001$ ]. There were no differences in relation to adverse reactions $(\mathrm{OR}=0.57,95 \% \mathrm{CI}: 0.31,1.07 ; \mathrm{P}=0.08)$, and the readmission rate between the experimental and control groups ( $\mathrm{OR}=0.94,95 \% \mathrm{CI}$ : 0.66, 1.34; $\mathrm{P}=0.75$ ).
\end{abstract}

Discussion: Corticosteroid use in the treatment of respiratory diseases in children can significantly shorten hospitalization time and increase the cure rate without increasing adverse reactions.

Keywords: Corticosteroids; acute respiratory disease; meta-analysis.

Submitted Nov 19, 2021. Accepted for publication Dec 30, 2021.

doi: $10.21037 / \mathrm{tp}-21-577$

View this article at: https://dx.doi.org/10.21037/tp-21-577

\section{Introduction}

Respiratory diseases in children include acute and chronic inflammation of the upper and lower respiratory tract, of which acute respiratory tract infection is the most common, and accounts for more than $60 \%$ of pediatric outpatient cases (1). Respiratory tract infections in children can be caused by viruses (mainly rhinovirus, respiratory syncytial virus, and influenza virus) or bacteria
$(2,3)$. Respiratory tract infections in children caused by viruses or bacteria can be treated with antibiotics (often penicillin and macrolides), and bronchodilators (e.g., salbutamol), which relax bronchial smooth muscles, dilate bronchi and relieve airflow limitation (4). Corticosteroids can reduce airway hyperresponsiveness, eliminate airway inflammation, repair damaged epithelium and promote the regeneration of airway cilia. They are often 
used in the treatment of acute asthma or asthma caused by respiratory tract infection. However, whether oral therapy or inhalation therapy, long-term treatment may affect the function of hypothalamic pituitary adrenal axis in asthmatic children, affecting children's growth and development (5). A research by Toogood (6) showed that for adult respiratory tract patients, the application of high-dose corticosteroids could more effectively reduce airway response than low-dose corticosteroids, but the inhibitory effect of adrenocortical function was more obvious. Therefore, when applied in children, the dosage of corticosteroids should be strictly limited. The results of a meta-analysis by Garrison et al. (7) showed that oral corticosteroids had a significant positive effect in children aged $<1$ year with respiratory disease by shortening the hospitalization time and symptom duration of children, and there were no obvious adverse reactions in short-term treatment. However, another randomized control trial (RCT) (8) found that oral corticosteroids had no significant effect in children aged 1-5 years. According to the meta-analysis carried out by Fernandes et al. (9), corticosteroids are effective in children with a few adverse event cases, but the administration methods limited to inhalation in this study, lacking of literatures on oral methods, and the quality and accuracy of the included studies are low. We conducted a metaanalysis of controlled clinical studies with better quality to determine the true effect and safety of corticosteroid drugs in the treatment of clinical pediatric respiratory diseases in children. We present the following article in accordance with the PRISMA reporting checklist (available at https:// tp.amegroups.com/article/view/10.21037/tp-21-577/rc).

\section{Methods}

\section{Inclusion of studies}

To be eligible for inclusion in the meta-analysis studies had to meet the following inclusion criteria: (I) be an RCT published after January 2000 in the language English (nonRCT studies of individual cases, guidelines, systematic analyses, and case-control studies were excluded); (II) comprise patients aged $<18$ years old, who had been diagnosed with acute respiratory tract infection, with or without wheezing symptoms, with runny nose and body temperature symptoms $\left(>37.5^{\circ} \mathrm{C}\right.$ ) (children with chronic asthma, tuberculosis, congenital heart disease, corticosteroid contraindications, and those who had receive any anti-inflammatory drug treatment before the study were excluded); (III) use one of the following intervention methods: randomization, double-blinded, placebocontrolled studies were preferred. Studties should have a sample size of $>10$ patients for both intervention and control group, in which the patients received the same basic treatment (i.e., disease assessment, data collection, antibiotic therapy, and bronchodilator therapy, such as salbutamol). For those in the experimental group patients received corticosteroid therapy (i.e., prednisone, methylprednisolone, hydrocortisone, dexamethasone, or budesonide) and those in the control group patients received placebos; 4) detail the outcome indicators, the statistical methods, and the data in the article, or have linkage for the data.

\section{Article search strategy}

The following databases were searched: Embase (January 2000 to August 2021), PubMed (January 2000 to August 2021), Web of Science (January 2000 to August 2021), Ovid (January 2000 to August 2021), and ClinicalTrials.org. The keyword rapid search method was used, and the input keywords were "corticosteroids" and "acute respiratory diseases."

\section{Selection of articles}

Two researchers independently screened the articles based on the above-mentioned criteria, and if any issues arose during this process, a 3 rd person was consulted for any contradiction.

\section{Data extraction}

Excel was used to extract data. The following data were extracted: (I) basic data about the article: publication time, author, and region; (II) characteristics of the study subjects: patient age, sex ratio, ethnicity, family history of asthma, history of hormone use, and initial Preschool Respiratory Assessment Measure (PRAM) score; (III) article intervention methods: the intervention methods of the 2 groups, and the observation time; and (IV) outcome data. In the process of data extraction, if the data were provided in the article, the data were accessed via the address specified in the article. If the data could not be obtained from the address, the original author of the article was contacted to obtain the data. If the data still could not be obtained, the article was excluded. 


\section{Outcome indicators}

The short-term efficacy indicators were as follows: (I) hospitalization rate; (II) proportion of patients who were not cured after treatment for 3 days; and (III) incidence rate of adverse reactions, including vomiting, maculopapular rash, diarrhea and restlessness. The long-term efficacy indicator was the readmission rate.

The following indicators were not subject to a statistical analysis: comparison of PRAM scores at 4,8 , and $12 \mathrm{~h}$ after treatment; the dosage of salbutamol during treatment, the proportion of cure after 7 days of treatment, the average time required for the symptoms to completely disappear, the serum hypersensitivity-C reactive protein (hsCRP) and interleukin (IL)-8 levels, and the number of days the patient presented with a cough. We did not perform a statistical analysis on these indicators as: (I) the number of articles reporting on some of the indicators was too small (e.g., only 1-2 articles reported on the dosage of salbutamol); (II) the reports on the indicators in different studies were not uniform (e.g., for salbutamol, some studies counted the dosage for 2 days, and some counted the dosage throughout the treatment).

\section{Statistical methods}

The $\mathrm{I}^{2}$ test analysis and $\mathrm{Q}$ test were used to examine the heterogeneity between the different studies. $\mathrm{A} \mathrm{I}^{2}$ value $<50 \%$ or a $\mathrm{P}$ value $\geq 0.1$ indicated that there was no statistically significant heterogeneity (or acceptable) heterogeneity between the articles. The mean difference (MD) was used to report the effect size for the continuous variables, and the odds ratio (OR) was used to report the effect size for binary variables. A $95 \%$ confidence interval (CI) was used. A P value $<0.05$ was considered statistically significant. The results are displayed in forest plots. For each outcome indicator, all of the articles included in the meta-analysis that reported on this indicator were combined for the statistical analysis. If there was no statistically significant heterogeneity, a fixed-effects model was used. If there was heterogeneity, a random-effects model was used. Revman 5.4 software provided by Cochrane was used as the analysis tool in this study to present the results. The publication bias is shown in the funnel plot.

\section{Risk of bias, heterogeneity survey, and sensitivity analysis}

The risk of bias assessment tool provided in Revman 5.4 was used for the analysis. The risk assessment of each article was performed in relation to 6 factors: randomization, allocation concealment, quality of blinding, outcome assessment, incomplete data, selective reporting, and other bias. If there was heterogeneity in the statistical process, the source of heterogeneity was examined by a subgroup analysis. If the source could not be confirmed, a general descriptive analysis was conducted. The sensitivity analysis was performed by comparing the results of the fixed-effects model with those of the random-effects model.

\section{Results}

\section{Article screening results}

Following the database search, 544 articles were initially retrieved, and 8 articles with 2,327 patients were ultimately included in the meta-analysis. Articles were excluded if the pulmonary infection was caused by other primary diseases (10), the sample size was too small (11), or the outcome indicators were not examined (12). Figure 1 shows the selection flow chart.

\section{Basic characteristics of articles}

The basic characteristics of the articles are set out in Table 1 . The subjects of the studies (13-20) were all children. The participants in a number of studies $(13,14,16-18)$ were preschool aged children, while other articles (15) only specified that the children were aged $<12$ years old, and 2 articles $(19,20)$ indicated that the children were aged $<1$ year old. The subjects of one study (15) were patients with community-acquired pneumonia, the subjects of two studies $(19,20)$ had acute respiratory syncytial virus bronchiolitis, and the subjects of the other studies were children with viral upper respiratory tract infection and asthma. Only two studies $(16,17)$ reported on the PRAM scores of the children before and after treatment. The shortest follow-up time was 7 days, and the longest was 3 months.

\section{Risk assessment of bias of included articles}

Revman 5.4 was used to conduct the risk assessment of the included articles. All of the articles included detailed descriptions of the random grouping method and drop-out cases. No selective reporting bias risk or other risk was found. One article (15) did not adopt the blind method, which increased the risk of implementation bias. One article (18) did not specify the use of allocation concealment or the blind method, which may indicate selective risk (see Figures 2,3). 


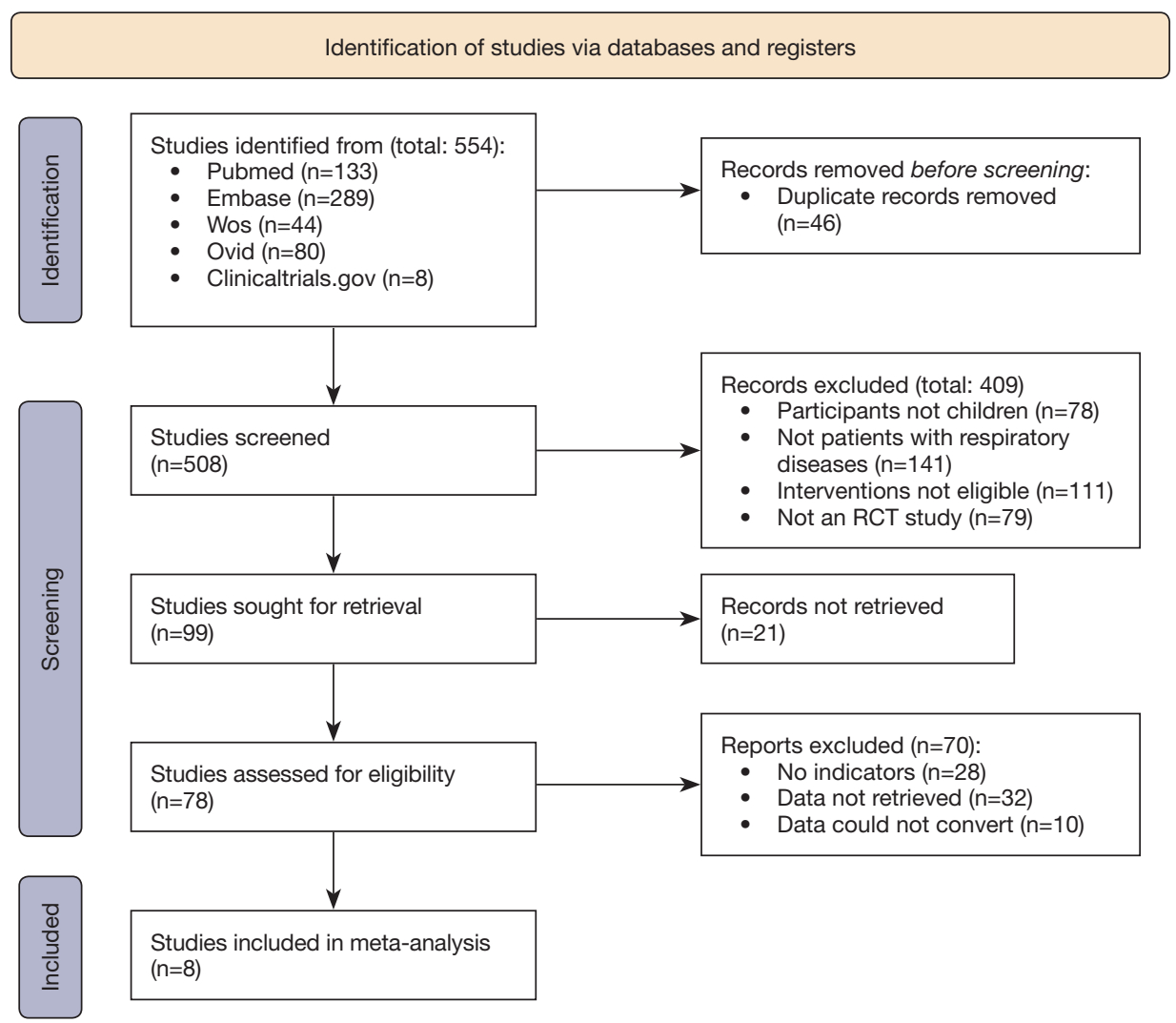

Figure 1 The selection flow chart.

\section{Meta-analysis results}

\section{Length of stay}

All of the included articles (13-20) reported on the length of the hospital stay (pediatric emergency room or general ward). As there was great heterogeneity between the articles $\left(\mathrm{I}^{2}=95 \%, \mathrm{P}<0.00001\right)$, the random-effects model was used. The length of hospital stay of the experimental group treated with corticosteroids was shorter than that of the control group (MD $=-2.03,95 \%$ CI: $-2.91,-1.14$; $\mathrm{P}<0.00001$; see Figure 4).

Based on the disease type of the children, the patients were further divided into 3 subgroups (i.e., the viral wheeze group, the community-acquired pneumonia group, and the viral respiratory bronchiolitis group). The results showed the use of corticosteroids shortened the length of hospital stay in the viral wheeze group ( $\mathrm{MD}=-2.26,95 \% \mathrm{CI}:-3.31$, $-1.22 ; \mathrm{P}<0.0001)$, the community-acquired pneumonia group $(\mathrm{MD}=-5.00,95 \% \mathrm{CI}:-7.03,-2.97 ; \mathrm{P}<0.0001)$, and the viral respiratory bronchiolitis group $(\mathrm{MD}=-0.56,95 \%$ CI: $-0.96,-0.15 ; \mathrm{P}=0.007)$.
Proportion of patients who did not recover after 3 days of treatment

Three articles (comprising a total of 1,519 patients) $(13,14,17)$ reported on the number and proportion of patients who did not recover after 3 days of treatment. The number of patients who did not recover after 3 days of treatment in the experimental group and the control group was 759 and 760, respectively. As there was no statistical heterogeneity between the articles $\left(\mathrm{I}^{2}=42 \%, \mathrm{P}=0.18\right)$, the fixed-effects model was used. Corticosteroid drug therapy reduced the number and proportion of uncured patients after 3 days of treatment $(\mathrm{OR}=0.55,95 \%$ CI: 0.42, 0.72; $\mathrm{P}<0.00001$; see Figure 5).

\section{Adverse reactions}

Four articles (13-16) reported on the adverse reactions of patients treated with corticosteroid drugs. As there was no statistical heterogeneity between the articles $\left(\mathrm{I}^{2}=0 \%\right.$, $\mathrm{P}=0.91$ ), the fixed-effects model was used. The adverse reactions of patients in the experimental group were not significantly different from those of patients in the control 


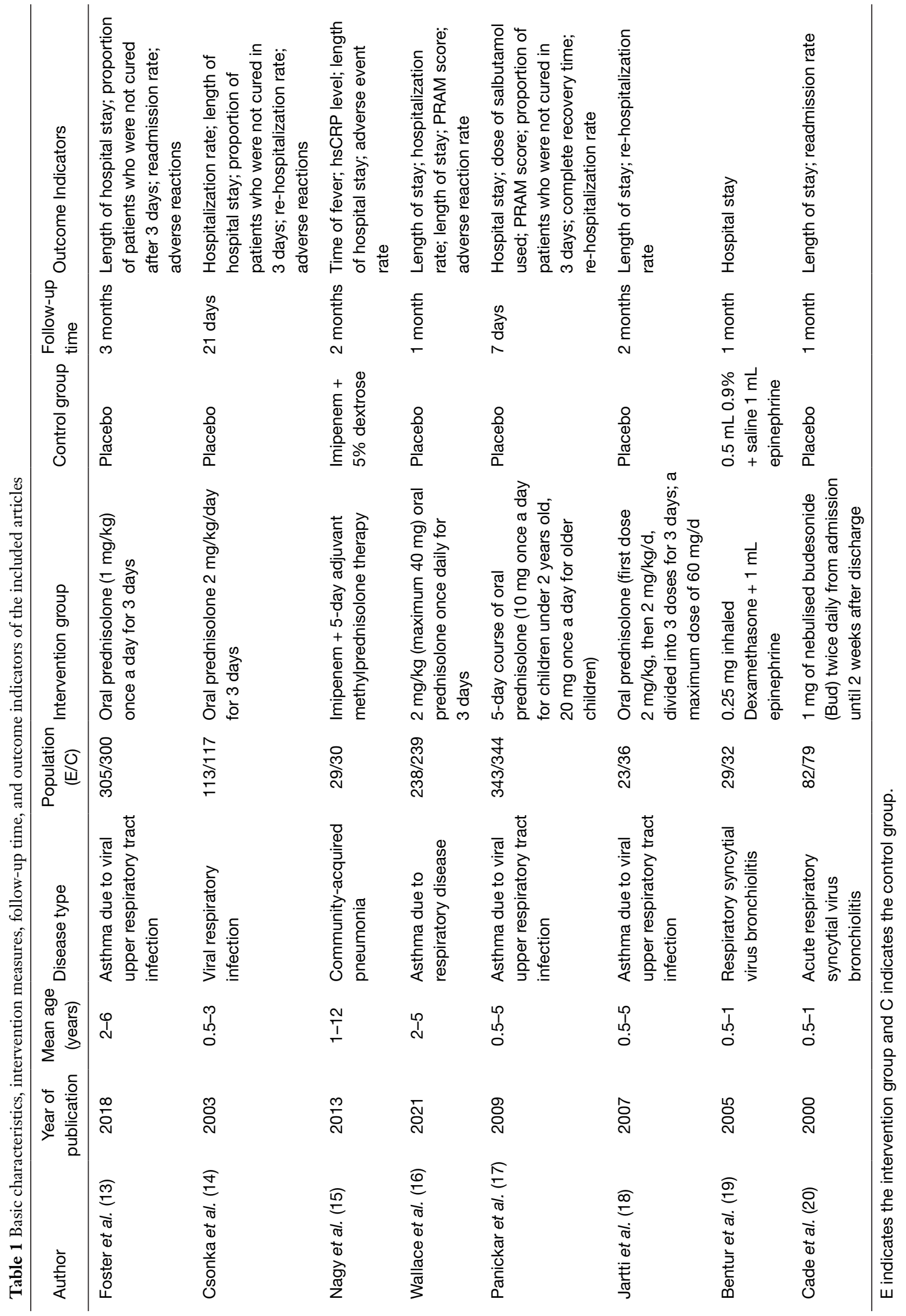




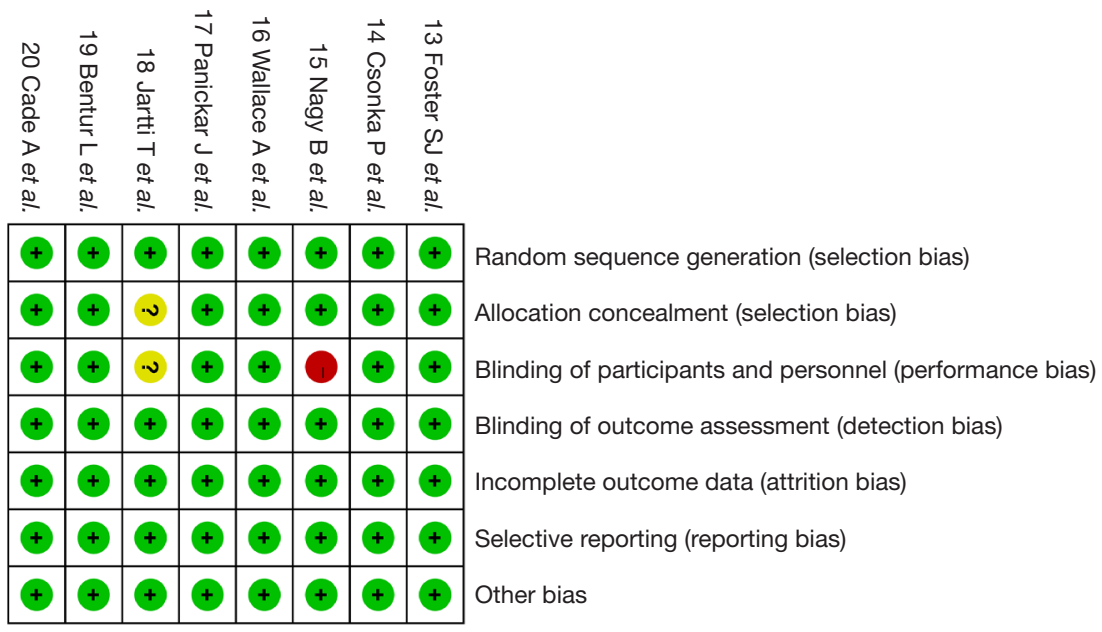

Figure 2 Summary chart of risk of bias assessment of included articles.

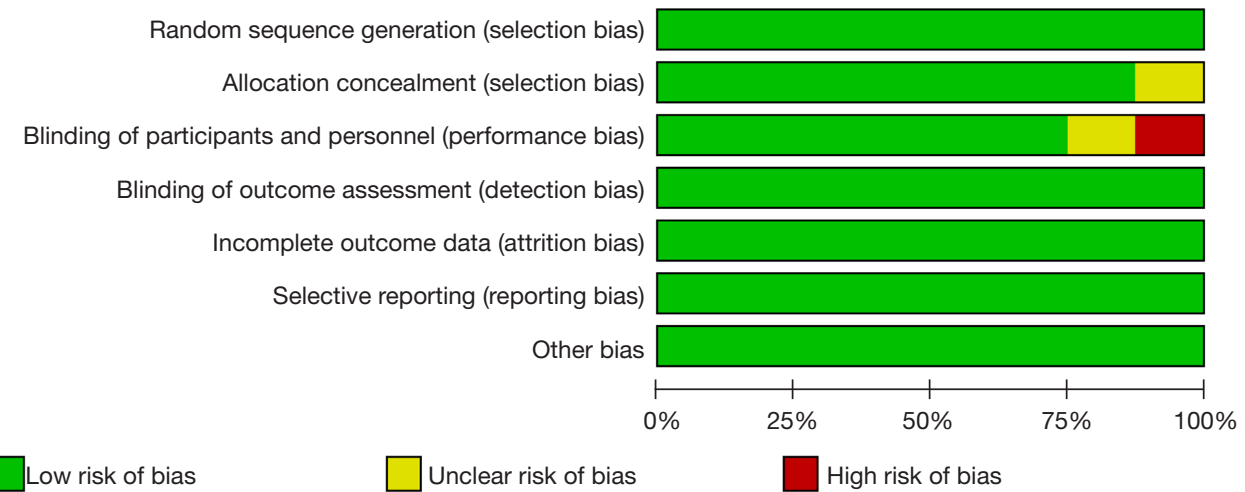

Figure 3 Risk of bias assessment chart of the included articles.

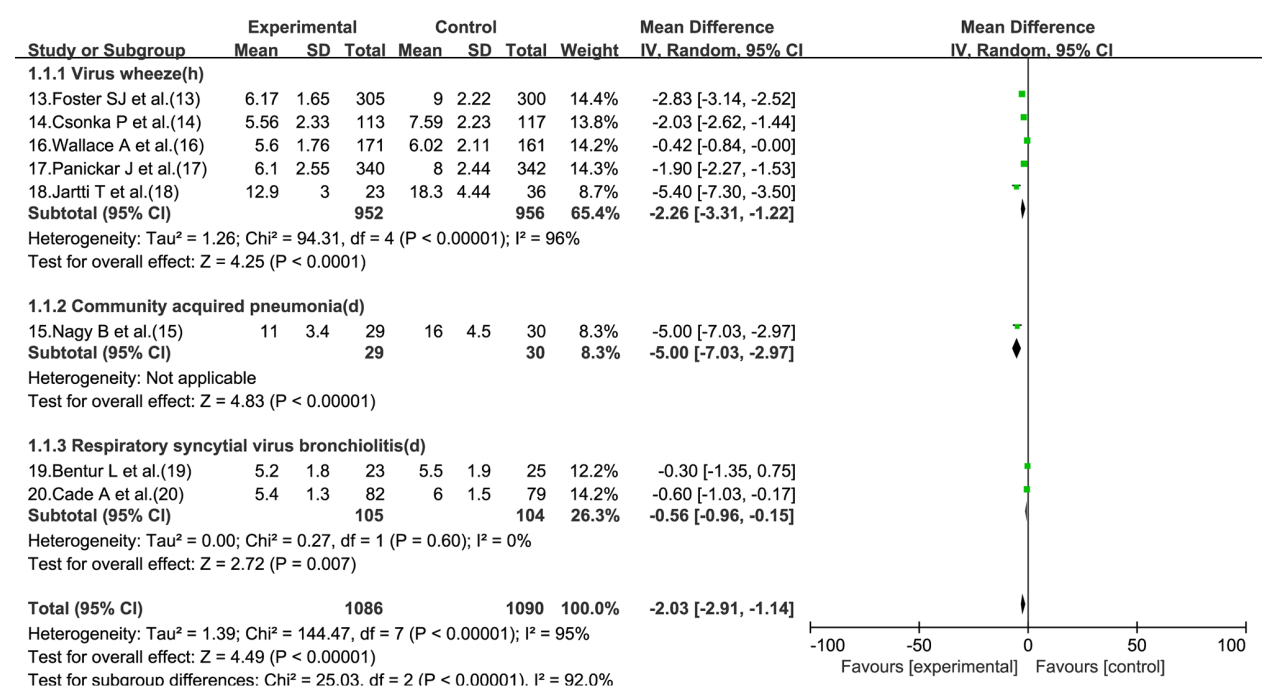

Figure 4 Effect of corticosteroid drugs on length of hospital stay in children with respiratory diseases. 


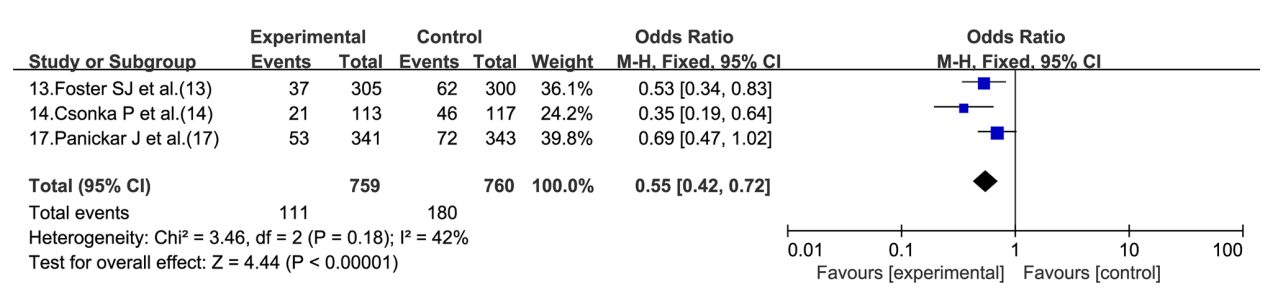

Figure 5 Effect of corticosteroid drugs on the number of children with respiratory diseases who were not cured after 3 days of treatment.

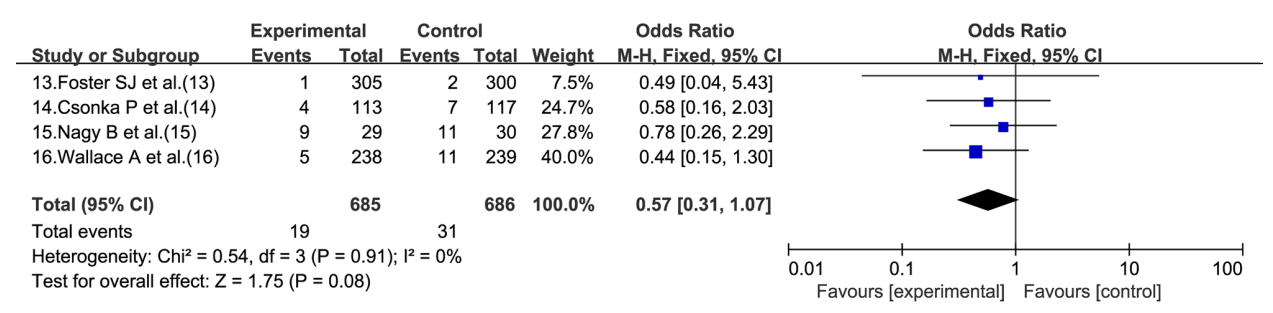

Figure 6 Adverse reactions of corticosteroids in children with respiratory disease.

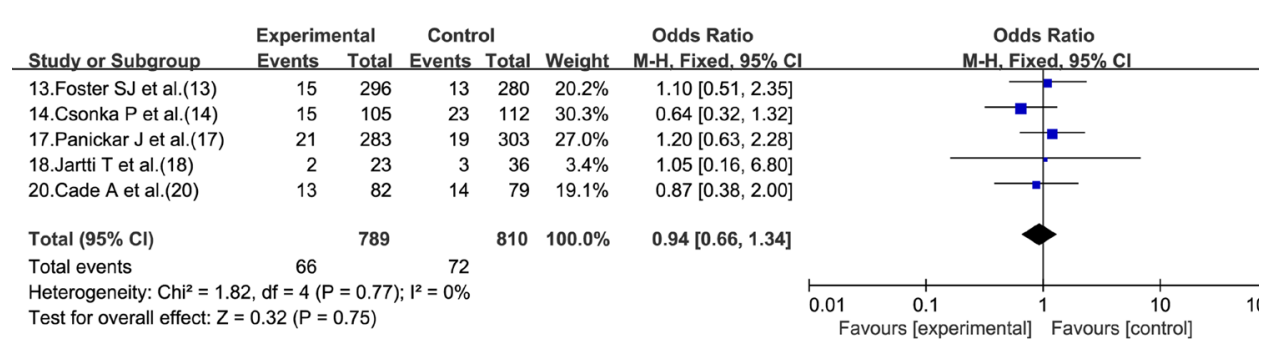

Figure 7 Effect of corticosteroids on the long-term re-hospitalization rate in children with respiratory diseases.

group (OR =0.57, 95\% CI: 0.31, 1.07; P=0.08; see Figure 6).

\section{Long-term efficacy: re-hospitalization rate}

Five articles $(13,14,17,18,20)$ reported on the rehospitalization rate of children after treatment. As there was no statistical heterogeneity between the articles $\left(\mathrm{I}^{2}=0 \%\right.$, $\mathrm{P}=0.77$ ), the fixed-effects model was used. The readmission rate of the experimental group did not differ significantly to that of the control group ( $\mathrm{OR}=0.94,95 \% \mathrm{CI}$ : 0.66, 1.34; $\mathrm{P}=0.75$; see Figure 7).

\section{Heterogeneity investigation and sensitivity analysis}

In the indicator analysis of the length of hospital stay, there was statistically significant heterogeneity among the articles. Thus, the articles were analyzed according to the type of disease. However, there was still heterogeneity among the articles in each subgroup. The source of heterogeneity may be related to multiple confounding factors, such as the age, race, and type and dose of the corticosteroid drugs. In the analysis of the re-hospitalization rate, when the random-effects model was used, the results did not differ significantly to those of the fixed-effects model; thus, the results can be considered stable (sensitivity analysis).

\section{Analysis of publication bias}

In the analysis of the re-hospitalization rate, the funnel plot showed that both sides were evenly distributed, which suggests that any publication bias was only small (see Figure 8).

\section{Discussion}

Eight articles, involving 4 kinds of corticosteroids (i.e., prednisolone, methylprednisolone, dexamethasone, 


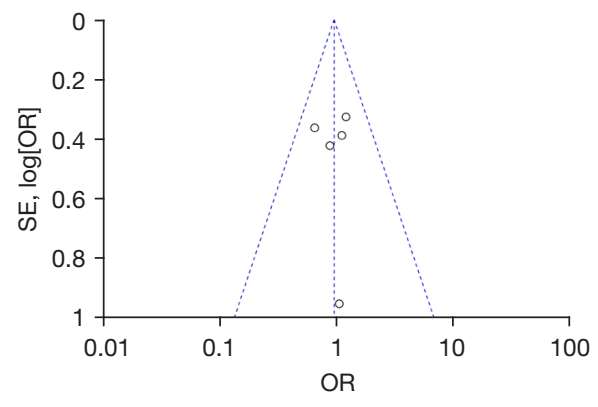

Figure 8 Funnel plot of corticosteroid therapy.

and budesonide) and 3 kinds of pediatric respiratory diseases (viral infection with asthma, community-acquired pneumonia, and viral respiratory bronchiolitis), were included in this study. Except for 1 article (15), the study subjects in the other articles were preschool aged children. Some studies $(16,17)$ have found that the effect of oral corticosteroids in treating pediatric respiratory diseases was not superior to placebos, but the results of the final comprehensive analysis showed that the experimental group treated with corticosteroids had shorter hospital stays and higher cure rates after 3 days of treatment than the placebo group, which suggests that treatment with corticosteroids significantly shortened the treatment time. In the long term, corticosteroid use did not further improve treatment outcomes (the readmission rate of the experimental group was similar to that of the placebo group), but the shortterm outcomes could still benefit children. Corticosteroid drugs have a powerful effect, allowing children to achieve an immunoprotective state in a short period, thereby improving symptoms (21). Some studies (22) have also shown that treatment with corticosteroid drugs can accelerate the digestion of the virus, improve the immune capacity of children, and reduce serum inflammation.

However, the heterogeneity analysis of the articles in this study showed that there were great differences in the types, doses, and indications of corticosteroid drugs, and the age of the children and the types of diseases were also important factors that cause heterogeneity. Thus, the safety of corticosteroid drugs requires further study. In this metaanalysis, 4 articles (13-16) reported on the children's adverse reactions to corticosteroid drugs. However, the results showed that oral corticosteroid drugs did not increase the adverse reactions, but also did not increase the long-term readmission rate of children. Strouse (23) concluded that while dexamethasone has been shown to be effective at reducing the duration of respiratory disease due to sickle cell anemia, the great risk of readmission for pain should limit its use; however, none of the studies in this metaanalysis reported that the use of corticosteroids caused an increase in pain.

Only 8 articles were included in this meta-analysis. The article quality was good; however, some of the articles did not use the blind method, which may have caused an implementation bias. The funnel plots revealed no publication bias, but the number of included articles was small, as was the sample size. Due to the heterogeneity of the articles, relevant higher quality large-sample size RCT studies need to be conducted to gather further evidence.

\section{Conclusions}

Eight articles were included in this meta-analysis. The results showed that the application of corticosteroids in the treatment of children with respiratory diseases significantly shortened hospitalization stay and increased the cure rate of patients without increasing adverse reactions.

\section{Acknowledgments}

Funding: None.

\section{Footnote}

Reporting Checklist: The authors have completed the PRISMA reporting checklist. Available at https:// tp.amegroups.com/article/view/10.21037/tp-21-577/rc

Conflicts of Interest: Both authors have completed the ICMJE uniform disclosure form (available at https://tp.amegroups. com/article/view/10.21037/tp-21-577/coif). The authors have no conflicts of interest to declare.

Ethical Statement: The authors are accountable for all aspects of the work in ensuring that questions related to the accuracy or integrity of any part of the work are appropriately investigated and resolved.

Open Access Statement: This is an Open Access article distributed in accordance with the Creative Commons Attribution-NonCommercial-NoDerivs 4.0 International License (CC BY-NC-ND 4.0), which permits the noncommercial replication and distribution of the article with 
the strict proviso that no changes or edits are made and the original work is properly cited (including links to both the formal publication through the relevant DOI and the license). See: https://creativecommons.org/licenses/by-nc-nd/4.0/.

\section{References}

1. Nascimento AP, Santos JM, Mill JG, et al. Association between the incidence of acute respiratory diseases in children and ambient concentrations of SO2, PM10 and chemical elements in fine particles. Environ Res 2020;188:109619.

2. Sharma BS, Shekhawat DS, Sharma P, et al. Acute Respiratory Distress in Children: Croup and Acute Asthma. Indian J Pediatr 2015;82:629-36.

3. Richardson AE, Warrier K, Vyas H. Respiratory complications of the rheumatological diseases in childhood. Arch Dis Child 2016;101:752-8.

4. Kavitha TK, Angurana SK. Long-Term Respiratory Morbidity Among Children With Acute Respiratory Failure: More to Discover. Crit Care Med 2020;48:e1368-e1369.

5. Mammen MJ, Aryal K, Alhazzani W, et al. Corticosteroids for patients with acute respiratory distress syndrome: a systematic review and meta-analysis of randomized trials. Pol Arch Intern Med 2020;130:276-86.

6. Toogood JH, Lefcoe NM, Haines DS, et al. A graded dose assessment of the efficacy of beclomethasone dipropionate aerosol for severe chronic asthma. J Allergy Clin Immunol. 1977;59:298-308.

7. Garrison MM, Christakis DA, Harvey E, et al. Systemic corticosteroids in infant bronchiolitis: a meta-analysis. Pediatrics 2000;105:E44.

8. Oommen A, Lambert PC, Grigg J. Efficacy of a short course of parent-initiated oral prednisolone for children aged 1-5 years: randomised controlled trial. Lancet 2003;362:1433-8.

9. Fernandes RM, Wingert A, Vandermeer B, et al. Safety of corticosteroids in young children with acute respiratory conditions: a systematic review and meta-analysis. BMJ Open. 2019;9:e028511.

10. Webb NJ, Frew E, Brettell EA, et al. Short daily course prednisolone therapy during an upper respiratory tract infection in children with relapsing steroid-sensitive nephrotic syndrome (PREDNOS 2): protocol for a randomised controlled trial. Trials 2014;15:147.

11. Bellodi S, Tosca MA, Pulvirenti G, et al. Activity of budesonide on nasal neutrophilic inflammation and obstruction in children with recurrent upper airway infections. A preliminary investigation. Int J Pediatr Otorhinolaryngol 2006;70:445-52.

12. van Woensel JB, Vyas H; STAR Trial Group. Dexamethasone in children mechanically ventilated for lower respiratory tract infection caused by respiratory syncytial virus: a randomized controlled trial. Crit Care Med 2011;39:1779-83.

13. Foster SJ, Cooper MN, Oosterhof S, et al. Oral prednisolone in preschool children with virus-associated wheeze: a prospective, randomised, double-blind, placebo-controlled trial (published correction appears in Lancet Respir Med. 2018 Jan 31;). Lancet Respir Med 2018;6:97-106.

14. Csonka P, Kaila M, Laippala P, et al. Oral prednisolone in the acute management of children age 6 to 35 months with viral respiratory infection-induced lower airway disease: a randomized, placebo-controlled trial. J Pediatr 2003;143:725-30.

15. Nagy B, Gaspar I, Papp A, et al. Efficacy of methylprednisolone in children with severe community acquired pneumonia. Pediatr Pulmonol 2013;48:168-75.

16. Wallace A, Sinclair O, Shepherd M, et al. Impact of oral corticosteroids on respiratory outcomes in acute preschool wheeze: a randomised clinical trial (published correction appears in Arch Dis Child. 2021 Mar 30;). Arch Dis Child 2021;106:339-44.

17. Panickar J, Lakhanpaul M, Lambert PC, et al. Oral prednisolone for preschool children with acute virusinduced wheezing. N Engl J Med 2009;360:329-38.

18. Jartti T, Lehtinen P, Vanto T, et al. Efficacy of prednisolone in children hospitalized for recurrent wheezing. Pediatr Allergy Immunol 2007;18:326-34.

19. Bentur L, Shoseyov D, Feigenbaum D, et al. Dexamethasone inhalations in RSV bronchiolitis: a double-blind, placebo-controlled study. Acta Paediatr 2005;94:866-71.

20. Cade A, Brownlee KG, Conway SP, et al. Randomised controlled trial of nebulised corticosteroids in acute respiratory syncytial viral bronchiolitis. Arch Dis Child 2000;82:126-130.

21. Silverman M, Sheffer AL, Díaz PV, et al. Safety and tolerability of inhaled budesonide in children in the Steroid Treatment As Regular Therapy in early asthma (START) trial. Pediatr Allergy Immunol 2006;17 Suppl 17:14-20. 
22. van Woensel JB, Lutter R, Biezeveld M, et al. Effect of dexamethasone on viral load and interleukin- 8 tracheal concentration in children with respiratory syncytial virus infection. Pediatr Infect Dis J 2003;22:721-6.

Cite this article as: Yang X, Jin H. Safety of corticosteroids in the treatment of acute respiratory disease in children: a systematic review and meta-analysis. Transl Pediatr 2022;11(2):194-203. doi: 10.21037/tp-21-577
23. Strouse JJ, Takemoto CM, Keefer JR, et al.

Corticosteroids and increased risk of readmission after acute chest syndrome in children with sickle cell disease. Pediatr Blood Cancer 2008;50:1006-12. 